Eleventh International Symposium on Flammability and Sensitivity of Materials in OxygenEnriched Atmospheres

\title{
Promoted Metals Combustion at Ambient and Elevated Temperatures
}

Carl D. Engel, Qualis Corporation

Stephen D. Herald, ICRC Aerospace Services

S. Eddie Davis. National Aeronautics and Space Administration/Marshall Space Flight Center

\begin{abstract}
Promoted combustion testing of materials, Test 17 of NASA STD-6001, has been used to assess metal propensity to burn in oxygen rich environments. An igniter is used at the bottom end of a rod to promote ignition, and if combustion is sustained, the burning progresses from the bottom to the top of the rod. The physical mechanisms are very similar to the upward flammability test, Test 1 of NASA STD-6001. The differences are in the normal environmental range of pressures, oxygen content, and sample geometry. Upward flammability testing of organic materials can exhibit a significant transitional region between no burning to complete quasi-state burning. In this transitional region, the burn process exhibits a probabilistic nature. This transitional region has been identified for metals using the promoted combustion testing method at ambient initial temperatures. The work given here is focused on examining the transitional region and the quasisteady burning region both at conventional ambient testing conditions and at elevated temperatures. A new heated promoted combustion facility and equipment at Marshall Space Flight Center have just been completed to provide the basic data regarding the metals operating temperature limits in contact with oxygen rich atmospheres at high pressures. Initial data have been obtained for Stainless Steel 304L, Stainless Steel 321, Haynes 214, and Inconel 718 at elevated temperatures in 100-percent oxygen atmospheres. These data along with an extended data set at ambient initial temperature test conditions are examined. The pressure boundaries of acceptable, non-burning usage is found to be lowered at elevated temperature.
\end{abstract}

Carl D. Engel, Qualis Corporation

Marshall Space Flight Center, EM10

Huntsville, AL 35812 USA

Phone: 256-544-6032; Fax: 256-544-2912

E-mail: Carl.D.Engel@msfc.nasa.gov

Stephen Herald, ICRC Aerospace Services

Marshall Space Flight Center, EM10

Huntsville, AL 35812 USA

Phone: 256-544-3885; Fax: 256-544-7372

E-mail: stephen.herald@msfc.nasa.gov

Eddie Davis, NASA/MSFC

Marshall Space Flight Center, EM10

Huntsville, AL 35812 USA

Phone: 256-544-2490; Fax: 256-544-7372

E-mail: eddie.davis@msfc.nasa.gov 
Carl D. Engel ${ }^{1}$, Stephen D. Herald ${ }^{2}$, and Samuel E. Davis ${ }^{3}$

\title{
Promoted Metals Combustion at Ambient and Elevated Temperatures
}

\begin{abstract}
Promoted combustion testing of materials, Test 17 of NASA Standard 6001 (NASASTD-6001), has been used to assess metal propensity to burn in oxygen-rich environments. An igniter at the bottom end of a rod promotes ignition, and if combustion is sustained, the burning progresses from the bottom to the top of the rod. The physical mechanisms are very similar to those of the upward flammability test, Test 1 of NASASTD-6001. The differences are in the normal environmental range of pressures, oxygen content, and sample geometry. Upward flammability testing of organic materials can exhibit a significant transitional region between no burning to complete quasi-state burning. In this transitional region, the burn process exhibits a probabilistic nature. This transitional region has been identified for metals using the promoted combustion testing method at ambient initial temperatures. The work herein is focused on examining the transitional region and the quasi-steady burning region both at conventional ambient testing conditions and at elevated temperatures.
\end{abstract}

A new heated promoted combustion facility and equipment at Marshall Space Flight Center (MSFC) has just been completed to provide the basic data on a metal's operating temperature limits in contact with oxygen-rich atmospheres at high pressures. Initial data have been obtained for stainless steel 304L, stainless steel 321 , Haynes ${ }^{\circledR} 214^{\mathrm{TM}}$, and Inconel ${ }^{\circledR} 718$ at elevated temperatures in 100-percent oxygen atmospheres. These data, along with an extended data set at ambient initial temperature test conditions, are examined. The pressure boundaries of acceptable, non-burning usage are found to be lowered at elevated temperatures.

Keywords: promoted ignition combustion, gaseous oxygen, high-temperature metals, flammability, transitional region; stainless steel 304L, 321, 347; Inconel ${ }^{\circledR} 718$ and X750, Haynes $^{\circledR} 214^{\mathrm{TM}}$, Incoloy 825.

\footnotetext{
${ }^{1}$ Director of Engineering and Research Specialist, Qualis Corporation, Marshall Space Flight Center/EM10, Huntsville, AL 35812

${ }^{2}$ Laboratory Chief Engineer, ICRC Aerospace Services, Marshall Space Flight Center/EM10, Huntsville, AL 35812

${ }^{3}$ Materials Engineer, Materials Compatibility Team, Chemistry Group, Materials Processes and Manufacturing Department, Marshall Space Flight Center/EM10, Huntsville, AL 35812
} 


\section{Background}

Promoted combustion testing of materials, Test 17 of NASA STD-6001 (Ref. 1), has been used to assess metal propensity to burn in oxygen-rich environments. An igniter at the bottom end of a rod is used to promote ignition, and if combustion is sustained, the burning progresses from the bottom to the top of the rod. Keys, et al., (Ref. 2) examined the database on the upward flammability of metals in GOX and came to a few basic conclusions from this large set of tests of many alloys. First, sample size was seen to be the greatest contributor to reproducibility of anomalies of pressure threshold values. Data generated from rod or sheet stock did not show a difference in oxygen pressure ignition thresholds. No significant differences in threshold values were observed in reviewing the historical (time) effect of the test conduct. The primary conclusion from this data review and analysis was that the data had a statistical characteristic that was not being investigated by sufficient tests at each condition; it was also recommended that the standard test be conducted with at least 10 samples at each environmental condition. This effort was focused on pressure effects alone and did not have data for metals at different initial temperature conditions.

The physical mechanisms of promoted combustion are very similar to those associated with the upward flammability test, Test 1 of NASA STD-6001, used for organic materials. The differences are in the normal environmental range of pressures, oxygen content, and sample geometry. The work of Engel, et al., (Ref. 3) demonstrated that upward flammability testing of organic materials can exhibit a significant transitional region between no burning to complete quasi-state burning. This transitional region has been identified by Zawierucha, et al., (Ref. 4) for metals using the promoted combustion testing method. Engel, et al., (Ref. 5) extended the definition of the transitional region for metals and showed that the transitional region is characterized by a burn length probability distribution. A material is characterized by a lower pressure region in which ignition and burning do not occur. This is followed by a pressure range where the length of burn is characterized by a probability distribution. The lowest pressure at which significant numbers of samples burn more than that promoted by the igniter is the ignition threshold pressure. Many samples are required to be tested at each pressure within this transitional region to define the distributions through the transitional region for each metal. At higher pressures, a sample will totally burn on a consistent basis. The burning rate is generally increased as a function of pressure in this region. Most all of the previous data and characterization have been accomplished at ambient initial temperature of the metal. Wilson and Stolzfus (Ref. 6) provide a recent review of metal flammability.

Two NASA facilities, MSFC and White Sands Test Facility (WSTF), have built two heated types of promoted combustion testers. The tester at MSFC is capable of testing metals at pressures up to $10,000 \mathrm{psia}(6.9 \mathrm{MPa})$ and temperatures exceeding $2,000^{\circ} \mathrm{F}$ $\left.\left(1,100{ }^{\circ} \mathrm{C}\right)\right]$. Both NASA and private industry have and are performing extensive ambient-temperature, high-pressure oxygen, promoted combustion/ignition materials testing. WSTF currently is performing this test in temperatures up to $500^{\circ} \mathrm{F}\left(260^{\circ} \mathrm{C}\right)$ but is limiting the pressure to $1,500 \mathrm{psia}(10.25 \mathrm{MPa})$. Both MSFC and WSTF can perform this test at ambient temperature at pressures up to $10,000 \mathrm{psia}(6.9 \mathrm{MPa})$. 
At present, two methods are available for achieving the high temperatures required for the High-Temperature High-Pressure Promoted Ignition-Combustion Test. The first method requires heating the entire test chamber, test atmosphere, and sample to the target temperature. The second method uses induction heating of the sample alone. The Materials Combustion Research Facility at MSFC in Huntsville, Alabama, has developed a new Heated Promoted Ignition-Combustion test system that overcomes many of the problems of previous designs by using the induction heating method.

\section{Heated Combustion Test Facility}

The direct heating method at MSFC uses an induction coil (Figure 1) housed inside the promoted ignition-combustion chamber (Figure 2), which is similar to the chamber described in ASTM 124-95. The MSFC induction-heated high-pressure promoted ignition-combustion chamber can sustain a pressure of up to $10,000 \mathrm{psia}(6.9 \mathrm{MPa})$ in pure gaseous oxygen and contains an induction coil capable of preheating a metal specimen to near its melting temperature [possibly in excess of $2,000^{\circ} \mathrm{F}\left(1,100^{\circ} \mathrm{C}\right)$ ], depending upon the test pressure. This improved test chamber gives important data in two needed areas, namely physical conditions and material properties accessible for experimentation, neither of which has been possible with previous test equipment.

The improved induction-coil design is not the only enhancement to the standard for the High-Temperature High-Pressure Promoted Ignition-Combustion Tester. Several other enhancements aid researchers in high-temperature metals combustion testing. The first of these, the measurement of the propagation rate of a burning sample, will allow a better understanding of this rate in the combustion processes of metals. The propagation rate is the rate at which the flame front travels along the sample, and it is usually recorded in inches per second or millimeters per second. The recording of this data, in the past, has been hampered by a limited number of sight ports for observing the combustion event. The standard test system as described in ASTM G124 has just one sight port located at the bottom of the chamber. This one port required the researcher to determine the propagation rate of the burning samples by the rate at which the molten droplets fell to the bottom of the chamber. To overcome this limitation, six sight ports were placed in the new chamber and arranged in a helical pattern to allow the observation of the combustion event for the entire length of the sample, up to a maximum sample length of 12 in. (305 $\mathrm{mm}$ ). Because of the high pressures involved in the test, these sight ports had to be constructed out of sapphire with a 1.3-in. (33-mm) thickness.

The second enhancement involves measuring the temperature of the sample as it burns. This temperature measurement presented a special problem because the induction field affects thermocouple data. To resolve this problem, an infrared transducer is used to measure the sample temperature remotely through each of the six sight ports. The transducer is calibrated to account for the sapphire sight port and the emissivity of the sample. 


\section{Scope of Testing}

The ambient initial temperature test equipment used was compliant with specifications in Test 17 of NASA STD-6001 (Ref. 1). Most of the ambient temperature data reported herein was obtained as part of the work to produce the results given by Key, et al., (Ref.

2) but not contained in the paper. Additional data were obtained for stainless steel 347 as part of this work. The ambient temperature data are contained in the NASA Marshall Space Flight Center Materials and Processes Technical Information System (MAPTIS) database (Ref. 7). The ambient initial temperature data examined herein are for stainless steel 347, stainless steel 17-7PH, Haynes ${ }^{\circledR} 214^{\mathrm{TM}}$, Inconel ${ }^{\circledR} \mathrm{X} 750$, and Incoloy 825 . All ambient temperature data reported herein were for 0.125 -in. $(0.3175-\mathrm{cm})$ diameter rods with a rod length of $12 \mathrm{in.}(30.48 \mathrm{~cm})$ in $100 \%$ oxygen.

To examine the effect of initial sample temperature on the burning characteristics of metals, four metals were selected to begin the characterization. A set of tests was performed for stainless steel 304L, stainless steel 321 , Haynes ${ }^{\circledR} 214^{\mathrm{TM}}$, and Inconel ${ }^{\circledR} 718$ in $100 \%$ oxygen at conditions from 70 to $1800{ }^{\circ} \mathrm{F}\left(21\right.$ to $\left.982^{\circ} \mathrm{C}\right)$ and 125 to 5000 psia (34.38 MPa). Rod geometry was also for 0.125 -in. $(0.3175-\mathrm{cm})$ diameter 12 in. (30.48 $\mathrm{cm}$ ) long rods, with the exception of the Inconel 718 rods. A 12 -in. $(30.48-\mathrm{cm})$ long by 0.125 -in $(0.3175-\mathrm{cm})$ octagonal rod was used for Inconel 718 .

\section{Test Results}

Standard Test 17 calls for the measurement of the burn length of the rod and the burning rate of the rod for the environmental conditions tested. Raw data for the burn length measurements of stainless steel 347 are presented in Figure 3 for pressures ranging from 350 to $1200 \mathrm{psia}$ ( 2.4 to $8.18 \mathrm{MPa}$ ). These data are typical of the metals examined here and by previous investigators. What is not typical is the number of samples at each pressure level. These data do not appear to correlate, and little or no pattern would emerge if significantly fewer data were obtained. Previous thinking was that below a certain threshold, no burning would occur and that at slightly higher pressure, the rod would be completely consumed. Earlier work represented (Ref. 5) introduced the concept of a transition zone. Upward flammability tests of organic materials showed that this transition zone could have significant width in the independent variable of oxygen concentration (Ref. 3). The transition zone is probabilistic in nature, and numerous test data points are required to characterize this zone. This work will illustrate that this zone exists in two dimensions of pressure and temperature for metals. The ambient data presented here will demonstrate how the transition zone can be characterized. The primary motivation is to determine the highest environmental conditions at which burning will not occur or the condition at which the material will self extinguish.

The data presented in Figure 3 can be used to calculate the cumulative distribution curve of the burn length at each pressure level. The data are shown in Figure 4. For example, at 800 psia, approximately $62 \%$ of the tested rods quenched and burned less than 6.0 in. (15 $\mathrm{cm})$. At 1000 psia, approximately $18 \%$ of the 41 rods self extinguished with burn lengths less than 6.0 in. $(15 \mathrm{~cm})$, but the other $82 \%$ burnt more than 6.0 in. $(15 \mathrm{~cm})$. Burning 
Carl D. Engel ${ }^{1}$, Stephen D. Herald ${ }^{2}$, and Samuel E. Davis ${ }^{3}$

\title{
Promoted Metals Combustion at Ambient and Elevated Temperatures
}

\begin{abstract}
Promoted combustion testing of materials, Test 17 of NASA Standard 6001 (NASASTD-6001), has been used to assess metal propensity to burn in oxygen-rich environments. An igniter at the bottom end of a rod promotes ignition, and if combustion is sustained, the burning progresses from the bottom to the top of the rod. The physical mechanisms are very similar to those of the upward flammability test, Test 1 of NASASTD-6001. The differences are in the normal environmental range of pressures, oxygen content, and sample geometry. Upward flammability testing of organic materials can exhibit a significant transitional region between no burning to complete quasi-state burning. In this transitional region, the burn process exhibits a probabilistic nature. This transitional region has been identified for metals using the promoted combustion testing method at ambient initial temperatures. The work herein is focused on examining the transitional region and the quasi-steady burning region both at conventional ambient testing conditions and at elevated temperatures.

A new heated promoted combustion facility and equipment at Marshall Space Flight Center (MSFC) has just been completed to provide the basic data on a metal's operating temperature limits in contact with oxygen-rich atmospheres at high pressures. Initial data have been obtained for stainless steel 304L, stainless steel 321 , Haynes ${ }^{\circledR} 214^{\mathrm{TM}}$, and Inconel ${ }^{\circledR} 718$ at elevated temperatures in 100-percent oxygen atmospheres. These data, along with an extended data set at ambient initial temperature test conditions, are examined. The pressure boundaries of acceptable, non-burning usage are found to be lowered at elevated temperatures.
\end{abstract}

Keywords: promoted ignition combustion, gaseous oxygen, high-temperature metals, flammability, transitional region; stainless steel 304L, 321, 347; Inconel ${ }^{\circledR} 718$ and X750, Haynes ${ }^{\circledR} 214^{\mathrm{TM}}$, Incoloy 825 .

${ }^{1}$ Director of Engineering and Research Specialist, Qualis Corporation, Marshall Space Flight Center/EM10, Huntsville, AL 35812

2 Laboratory Chief Engineer, ICRC Aerospace Services, Marshall Space Flight Center/EM10, Huntsville, AL 35812

${ }^{3}$ Materials Engineer, Materials Compatibility Team, Chemistry Group, Materials Processes and Manufacturing Department, Marshall Space Flight Center/EM10, Huntsville, AL 35812 


\section{Background}

Promoted combustion testing of materials, Test 17 of NASA STD-6001 (Ref. 1), has been used to assess metal propensity to burn in oxygen-rich environments. An igniter at the bottom end of a rod is used to promote ignition, and if combustion is sustained, the burning progresses from the bottom to the top of the rod. Keys, et al., (Ref. 2) examined the database on the upward flammability of metals in GOX and came to a few basic conclusions from this large set of tests of many alloys. First, sample size was seen to be the greatest contributor to reproducibility of anomalies of pressure threshold values. Data generated from rod or sheet stock did not show a difference in oxygen pressure ignition thresholds. No significant differences in threshold values were observed in reviewing the historical (time) effect of the test conduct. The primary conclusion from this data review and analysis was that the data had a statistical characteristic that was not being investigated by sufficient tests at each condition; it was also recommended that the standard test be conducted with at least 10 samples at each environmental condition. This effort was focused on pressure effects alone and did not have data for metals at different initial temperature conditions.

The physical mechanisms of promoted combustion are very similar to those associated with the upward flammability test, Test 1 of NASA STD-6001, used for organic materials. The differences are in the normal environmental range of pressures, oxygen content, and sample geometry. The work of Engel, et al., (Ref. 3) demonstrated that upward flammability testing of organic materials can exhibit a significant transitional region between no burning to complete quasi-state burning. This transitional region has been identified by Zawierucha, et al., (Ref. 4) for metals using the promoted combustion testing method. Engel, et al., (Ref. 5) extended the definition of the transitional region for metals and showed that the transitional region is characterized by a burn length probability distribution. A material is characterized by a lower pressure region in which ignition and burning do not occur. This is followed by a pressure range where the length of burn is characterized by a probability distribution. The lowest pressure at which significant numbers of samples burn more than that promoted by the igniter is the ignition threshold pressure. Many samples are required to be tested at each pressure within this transitional region to define the distributions through the transitional region for each metal. At higher pressures, a sample will totally burn on a consistent basis. The burning rate is generally increased as a function of pressure in this region. Most all of the previous data and characterization have been accomplished at ambient initial temperature of the metal. Wilson and Stolzfus (Ref. 6) provide a recent review of metal flammability.

Two NASA facilities, MSFC and White Sands Test Facility (WSTF), have built two heated types of promoted combustion testers. The tester at MSFC is capable of testing metals at pressures up to $10,000 \mathrm{psia}(6.9 \mathrm{MPa})$ and temperatures exceeding $2,000^{\circ} \mathrm{F}$ $\left.\left(1,100^{\circ} \mathrm{C}\right)\right]$. Both NASA and private industry have and are performing extensive ambient-temperature, high-pressure oxygen, promoted combustion/ignition materials testing. WSTF currently is performing this test in temperatures up to $500^{\circ} \mathrm{F}\left(260{ }^{\circ} \mathrm{C}\right)$ but is limiting the pressure to $1,500 \mathrm{psia}(10.25 \mathrm{MPa})$. Both MSFC and WSTF can perform this test at ambient temperature at pressures up to $10,000 \mathrm{psia}(6.9 \mathrm{MPa})$. 
At present, two methods are available for achieving the high temperatures required for the High-Temperature High-Pressure Promoted Ignition-Combustion Test. The first method requires heating the entire test chamber, test atmosphere, and sample to the target temperature. The second method uses induction heating of the sample alone. The Materials Combustion Research Facility at MSFC in Huntsville, Alabama, has developed a new Heated Promoted Ignition-Combustion test system that overcomes many of the problems of previous designs by using the induction heating method.

\section{Heated Combustion Test Facility}

The direct heating method at MSFC uses an induction coil (Figure 1) housed inside the promoted ignition-combustion chamber (Figure 2), which is similar to the chamber described in ASTM 124-95. The MSFC induction-heated high-pressure promoted ignition-combustion chamber can sustain a pressure of up to $10,000 \mathrm{psia}(6.9 \mathrm{MPa})$ in pure gaseous oxygen and contains an induction coil capable of preheating a metal specimen to near its melting temperature [possibly in excess of $2,000^{\circ} \mathrm{F}\left(1,100^{\circ} \mathrm{C}\right)$ ], depending upon the test pressure. This improved test chamber gives important data in two needed areas, namely physical conditions and material properties accessible for experimentation, neither of which has been possible with previous test equipment.

The improved induction-coil design is not the only enhancement to the standard for the High-Temperature High-Pressure Promoted Ignition-Combustion Tester. Several other enhancements aid researchers in high-temperature metals combustion testing. The first of these, the measurement of the propagation rate of a burning sample, will allow a better understanding of this rate in the combustion processes of metals. The propagation rate is the rate at which the flame front travels along the sample, and it is usually recorded in inches per second or millimeters per second. The recording of this data, in the past, has been hampered by a limited number of sight ports for observing the combustion event. The standard test system as described in ASTM G124 has just one sight port located at the bottom of the chamber. This one port required the researcher to determine the propagation rate of the burning samples by the rate at which the molten droplets fell to the bottom of the chamber. To overcome this limitation, six sight ports were placed in the new chamber and arranged in a helical pattern to allow the observation of the combustion event for the entire length of the sample, up to a maximum sample length of 12 in. (305 $\mathrm{mm})$. Because of the high pressures involved in the test, these sight ports had to be constructed out of sapphire with a 1.3-in. (33-mm) thickness.

The second enhancement involves measuring the temperature of the sample as it burns. This temperature measurement presented a special problem because the induction field affects thermocouple data. To resolve this problem, an infrared transducer is used to measure the sample temperature remotely through each of the six sight ports. The transducer is calibrated to account for the sapphire sight port and the emissivity of the sample. 


\section{Scope of Testing}

The ambient initial temperature test equipment used was compliant with specifications in Test 17 of NASA STD-6001 (Ref. 1). Most of the ambient temperature data reported herein was obtained as part of the work to produce the results given by Key, et al., (Ref. 2) but not contained in the paper. Additional data were obtained for stainless steel 347 as part of this work. The ambient temperature data are contained in the NASA Marshall Space Flight Center Materials and Processes Technical Information System (MAPTIS) database (Ref. 7). The ambient initial temperature data examined herein are for stainless steel 347, stainless steel 17-7PH, Haynes ${ }^{\circledR} 214^{\mathrm{TM}}$, Inconel ${ }^{\circledR}$ X750, and Incoloy 825 . All ambient temperature data reported herein were for 0.125 -in. $(0.3175-\mathrm{cm})$ diameter rods with a rod length of 12 in. $(30.48 \mathrm{~cm})$ in $100 \%$ oxygen.

To examine the effect of initial sample temperature on the burning characteristics of metals, four metals were selected to begin the characterization. A set of tests was performed for stainless steel $304 \mathrm{~L}$, stainless steel 321 , Haynes ${ }^{\circledR} 214^{\mathrm{TM}}$, and Inconel ${ }^{\circledR} 718$ in $100 \%$ oxygen at conditions from 70 to $1800^{\circ} \mathrm{F}\left(21\right.$ to $\left.982^{\circ} \mathrm{C}\right)$ and 125 to 5000 psia (34.38 MPa). Rod geometry was also for 0.125 -in. $(0.3175-\mathrm{cm})$ diameter 12 in. (30.48 $\mathrm{cm})$ long rods, with the exception of the Inconel 718 rods. A 12 -in. $(30.48-\mathrm{cm})$ long by 0.125 -in $(0.3175-\mathrm{cm})$ octagonal rod was used for Inconel 718 .

\section{Test Results}

Standard Test 17 calls for the measurement of the burn length of the rod and the burning rate of the rod for the environmental conditions tested. Raw data for the burn length measurements of stainless steel 347 are presented in Figure 3 for pressures ranging from 350 to $1200 \mathrm{psia}$ (2.4 to $8.18 \mathrm{MPa}$ ). These data are typical of the metals examined here and by previous investigators. What is not typical is the number of samples at each pressure level. These data do not appear to correlate, and little or no pattern would emerge if significantly fewer data were obtained. Previous thinking was that below a certain threshold, no burning would occur and that at slightly higher pressure, the rod would be completely consumed. Earlier work represented (Ref. 5) introduced the concept of a transition zone. Upward flammability tests of organic materials showed that this transition zone could have significant width in the independent variable of oxygen concentration (Ref. 3). The transition zone is probabilistic in nature, and numerous test data points are required to characterize this zone. This work will illustrate that this zone exists in two dimensions of pressure and temperature for metals. The ambient data presented here will demonstrate how the transition zone can be characterized. The primary motivation is to determine the highest environmental conditions at which burning will not occur or the condition at which the material will self extinguish.

The data presented in Figure 3 can be used to calculate the cumulative distribution curve of the burn length at each pressure level. The data are shown in Figure 4. For example, at 800 psia, approximately $62 \%$ of the tested rods quenched and burned less than $6.0 \mathrm{in}$. (15 $\mathrm{cm})$. At 1000 psia, approximately $18 \%$ of the 41 rods self extinguished with burn lengths less than 6.0 in. $(15 \mathrm{~cm})$, but the other $82 \%$ burnt more than 6.0 in. $(15 \mathrm{~cm})$. Burning 
more than $6.0 \mathrm{in} .(15 \mathrm{~cm})$ does not mean that the sample will be completely consumed, but quenching may occur after more than a 6.0 -in. $(15-\mathrm{cm})$ burn and before the rod is consumed. The cumulative distribution curves move from the upper left of the plot to the lower right hand side. The behavior appears probabilistic but well behaved if significant samples are tested.

Cumulative distribution curves are presented in Figures 5, 6, and 7 for Incoloy 825, Haynes ${ }^{\circledR} 214^{\mathrm{TM}}$, and Inconel ${ }^{\circledR} \mathrm{X} 750$, respectively. Each curve is based on a set of 10 samples at each pressure. The behavior is the same as for stainless steel 347. The small sample size of 10 samples produces the stair step character of the curves. It is evident that the use of 10 samples is truly a minimum to obtain the general character of the cumulative distribution curve and that more samples are required to obtain an accurate curve.

Based on the test sets available, the average burn length at each pressure was calculated for each metal at each tested pressure. The average burn length can be used to compare the propensity of the different metals to burn at the same condition. These data are shown in Figure 8. Stainless steel 17-7PH data are shown along with the data from the other metals discussed. These data show that the two stainless steels exhibit approximately the same burning characteristics. Incoloy, Haynes ${ }^{\circledR}$, and Inconel ${ }^{\circledR}$ are progressively capable of operation at higher pressures without burning. Even though the general ranking is established, the precise curves for each of the metals are not precise because of lack of data at additional pressure levels.

By considering and testing the effect of rod initial temperature, another variable is introduced. This increases the overall sample size requirement to characterize a material. A set of tests was conducted to explore the effects of temperature and pressure on the boundaries of flammability. The burn data are shown in Figures 9 and 10 for stainless steels $304 \mathrm{~L}$ and 321 , respectively. Previous testing had focused along the $70^{\circ} \mathrm{F}\left(21^{\circ} \mathrm{C}\right)$ line found on these plots. To obtain the cumulative distribution curves at a set of constant temperature conditions would require a larger sample size than initially available. The intent here was to experimentally define the no burn region, transitional region and the region where total burns were to be expected.

The "no burn" and "total burn" boundaries shown in Figures 9 and 10 are hand-faired curves. Each point on the plot (Figure 10) can be represented by a cumulative distribution curve developed from at least 10 samples. The current effort did not allow for such extensive testing. Notes are given on the figure to denote the point sample size and result. The designation TB/PB/NS represents the number of total burns/number of partial burns/total number of samples tested. Similar data plots are given for Haynes ${ }^{\circledR}$ $214^{\mathrm{TM}}$ and Inconel ${ }^{\circledR} 718$ in Figures 11 and 12, respectively. The stainless steels and Inconel ${ }^{\circledR}$ exhibit similar transition regions but Haynes ${ }^{\circledR} 214^{\mathrm{TM}}$ exhibits a transition region that appears to collapse at high temperature at a threshold pressure of about 600 psia. The threshold pressure at which the no burning region occurs is significantly reduced for all metals tested by elevated temperatures. At $1000^{\circ} \mathrm{F}\left(537.8^{\circ} \mathrm{C}\right)$, the no burning 
pressure threshold reduction was a factor of 1.6 for Haynes ${ }^{\circledR} 214^{\mathrm{TM}}, 1.7$ for Inconel ${ }^{\circledR} 718$, and 1.9 for stainless steels $304 \mathrm{~L}$ and 321.

The current heated combustion chamber has six site ports that allow continuous photographic monitoring of the sample. This permits accurate measurement of the burning rate. Burning rate data taken from total burn samples for each of the metals were examined and correlated. It is assumed that only the total burn runs established a quasisteady burning condition. Werley and Hansel (Ref. 8) warned that burn length needed to be significant for quasi-steady conditions to be established. The burn rate was found to be a function of pressure and rod initial temperature. The correlated data are presented in Figure 13 where the rate is a linear function of temperature and follows pressure to a power. Table 1 presents burn rate coefficients as derived with the following equation: where:

$$
\text { Burn rate }=r=(C T+D) P^{n} \quad(\text { in. } / s e c)
$$

$$
\begin{aligned}
& \mathrm{T}=\text { Temperature }\left({ }^{\circ} \mathrm{F}\right) \\
& \mathrm{P}=\text { Pressure }(\mathrm{psia}) \\
& \mathrm{R}^{2}=\text { Fit quality }
\end{aligned}
$$

Table 1. Burn Rate Coefficients

\begin{tabular}{|l|l|l|l|l|}
\hline Metal & C & D & n & $\mathbf{R}^{2}$ \\
\hline Stainless steel 304L & $1.58 \mathrm{E}-5$ & 0.0109 & 0.48 & 0.948 \\
\hline Stainless steel 321 & $1.39 \mathrm{E}-5$ & 0.0134 & 0.47 & 0.895 \\
\hline Haynes $^{\circledR} 214^{\mathrm{TM}}$, & $1.44 \mathrm{E}-4$ & 0.150 & 0.071 & 0.954 \\
\hline Inconel $^{\circledR} 718$ & $7.88 \mathrm{E}-5$ & 0.237 & 0.095 & 0.932 \\
\hline
\end{tabular}

Stainless steel 304L and 321 exhibit essentially the same burn rate dependence and are strongly dependent on pressure and weakly dependent upon temperature. Haynes ${ }^{\circledR}$ and Inconel ${ }^{\circledR}$ are both weakly dependent upon pressure and more strongly dependent upon temperature than stainless steels.

\section{Conclusions}

Based on the data examined, the following conclusions are drawn:

1) Upward flammability of metals data exhibits "no burn," "transitional," and "total burn" regions.

2) The characteristics of burning in the transitional region can be described in terms of cumulative burn length distributions. A minimum of 10 samples is required to define the cumulative distribution for one temperature and pressure set.

3) The transitional region exists in both pressure and temperature space for $100 \%$ oxygen environments. Based on upward flammability test data of organic materials, this transitional region is expected to be extended to concentration space for oxygen mixtures. 
4) The new induction-coil heating method of testing samples provides a way to experimentally expand the range of test conditions to real environmental conditions of working metals in systems.

5) The test data show that the safe, no-burn region for metals is significantly reduced at elevated operating temperatures. The safety margins once thought to be designed into systems should be reexamined based on data that can now be obtained.

\section{Acknowledgements}

The authors would like to gratefully acknowledge Dean Byess, Qualis Corporation, for his superior work in producing the test data and installing the new heated combustion facility.

\section{References}

1. NASA-STD-6001, Flammability, Odor, Offgassing, and Compatibility Requirements and Test Procedures for Materials in Environments that Support Combustion, Test 17, Upward Flammability of Materials in GOX, National Aeronautics and Space Administration, February 1998.

2. Key, C.F., Lowery, F.S., Darby, S.P., and Libb, R.S. "Factors Affecting the Reproducibility of Upward Propagation Pressure Thresholds of Metals in Gaseous Oxygen," Flammability and Sensitivity of Materials in Oxygen-Enriched Atmospheres: Eighth Volume, ASTM STP 1319, W.T. Royals, T.C. Chou, and T.A. Steinberg, Eds., ASTM International, West Conshohocken, PA, 1997.

3. Engel, C.D., Davis, S.E., and Richardson, E.H., "Upward Flammability Testing - A Probabilistic Measurement," Flammability and Sensitivity of Materials in OxygenEnriched Atmospheres: Tenth Volume, ASTM STP 1454, T.A. Steinberg, H.D. Beeson, and B.E. Newton, Eds., ASTM International, West Conshohocken, PA, 2003.

4. Zawierucha, R., McIlroy, K., and R. Mazzarella, "Promoted Ignition-Combustion Behavior of Selected Hastelloys in Oxygen Gas Mixtures," Flammability and Sensitivity of Materials in Oxygen-Enriched Atmospheres: Fifth Volume, STP 1111, ASTM International, West Conshohocken, PA, 1991.

5. Engel, Carl D., Davis, Samuel E., and Richardson, Erin H., Examination of Promoted Combustion Burn Characteristics, $7^{\text {th }}$ International Workshop on Microgravity Combustion and Chemically Reacting Systems, June 2003.

6. Wilson, D. B., and Stolzfus, Joel M., "Metal Flammability: Review and Model Analysis," Flammability and Sensitivity of Materials in Oxygen-Enriched Atmospheres: Eighth Volume, ASTM STP 1319, W.T. Royals, T.C. Chou and T.A. Steinberg, Eds., ASTM International, West Conshohocken, PA, 1997.

7. Materials and Processes Technical Information System, NASA Marshall Space Flight Center, EM03, Huntsville, AL 35812. Contact D.E. Griffin/EM03.

8. Werley, B. L., and Hansel, J. G., "Flammability Limits of Stainless Steel Alloys 304, 308, and 316," Flammability and Sensitivity of Materials in Oxygen-Enriched 
Atmospheres: , ASTM STP 1319, William T. Royals, Ting C. Chow and T. A. Steinberg, Eds., ASTM International, West Conshohocken, PA, 1997.

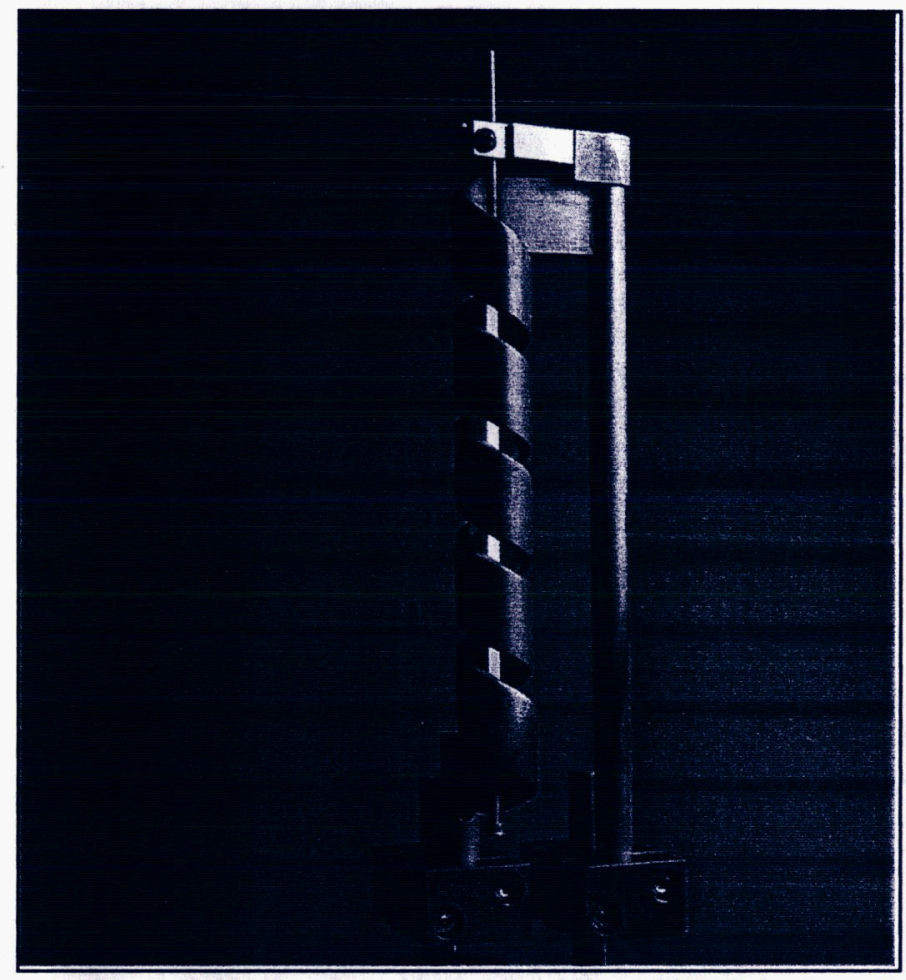

Figure 1. Sample being heated using the MSFC induction coil

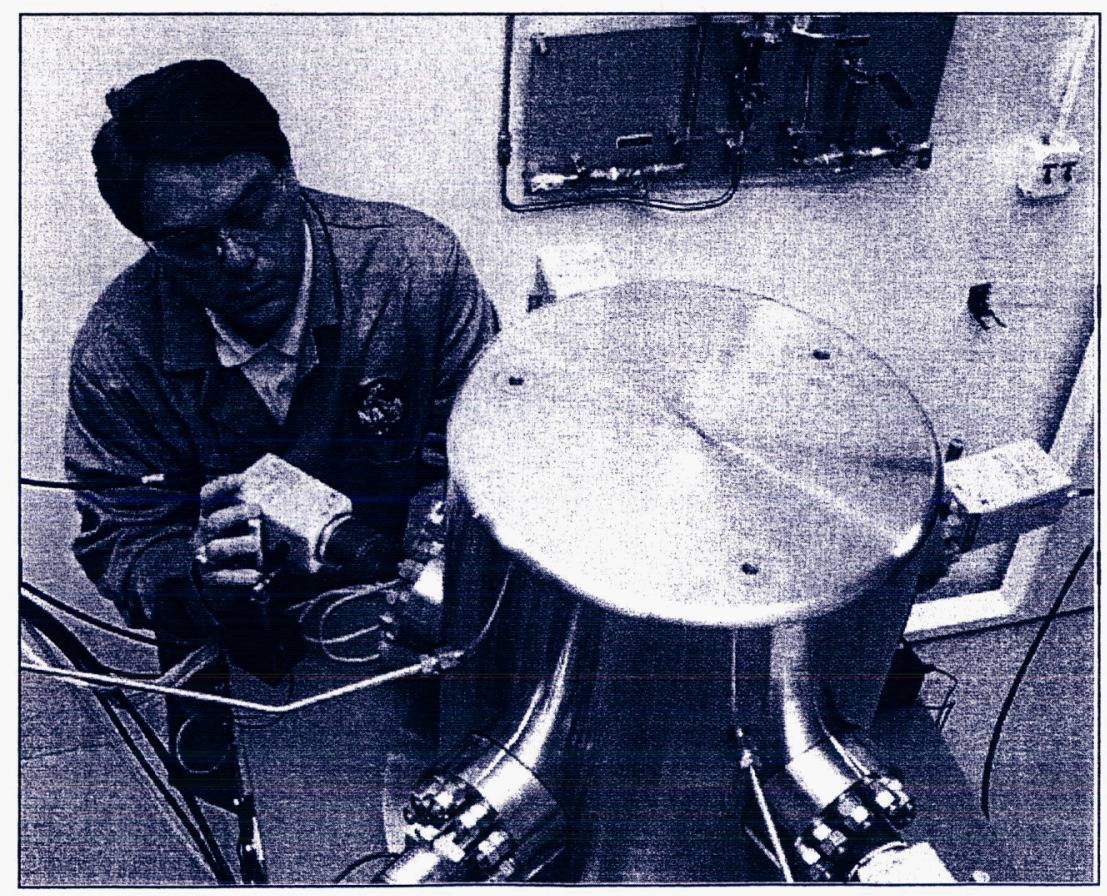

Figure 2. Engineer aligning one of six cameras in the chamber view port. 


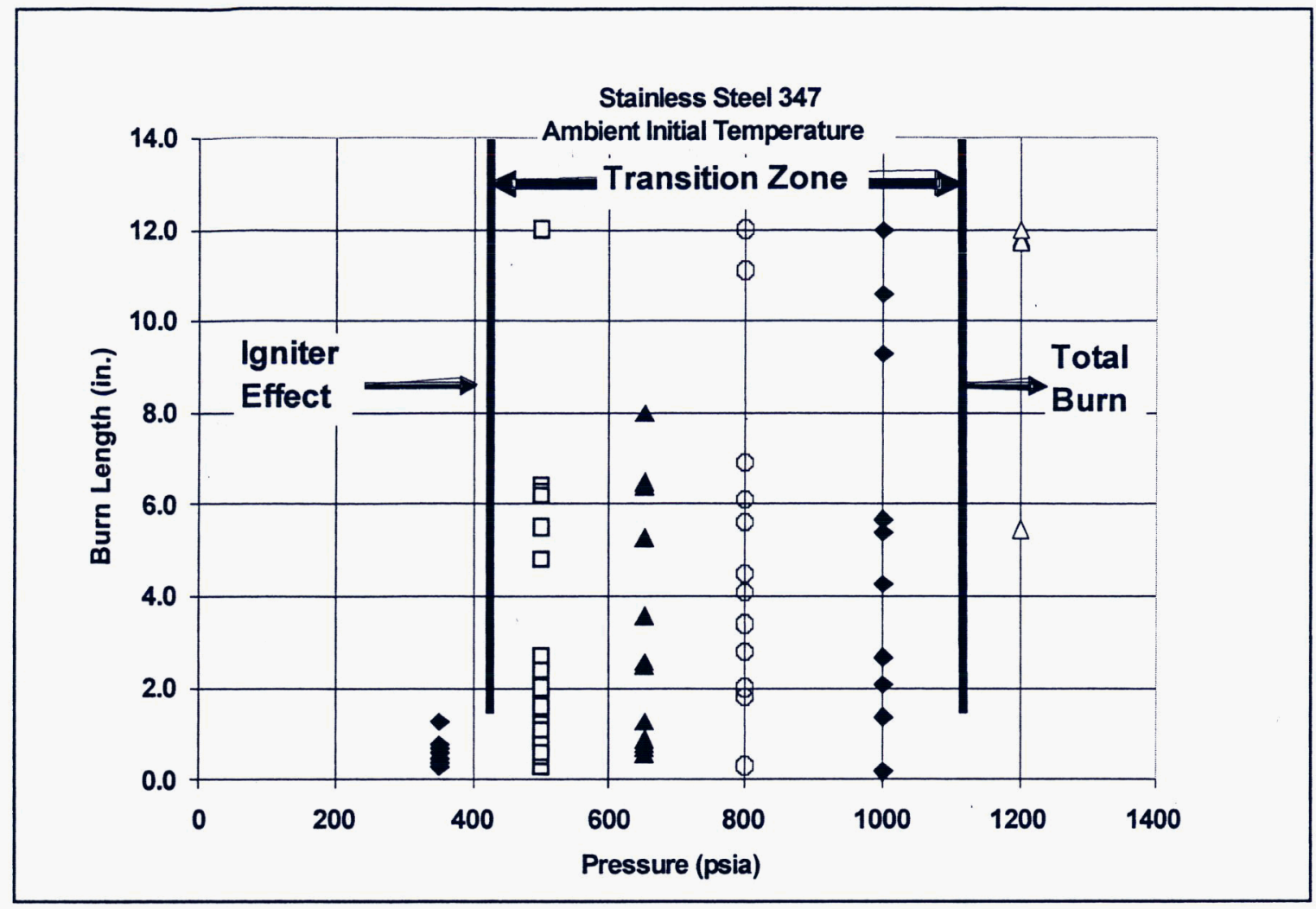

Figure 3. Raw Promoted Combustion Burn Length Data for Stainless Steel 347

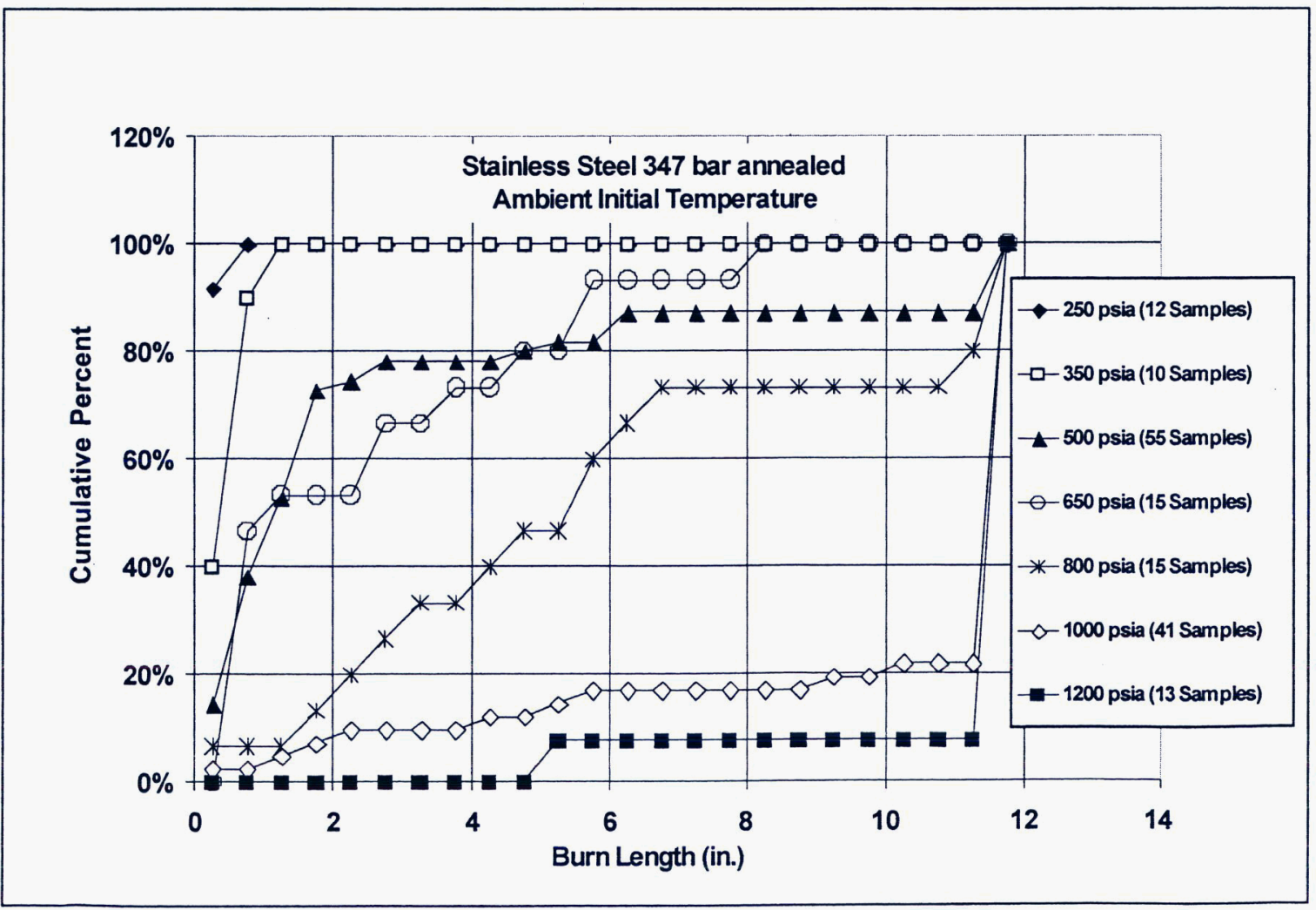

Figure 4. Stainless Steel 347 Cumulative Burn Length Distributions 


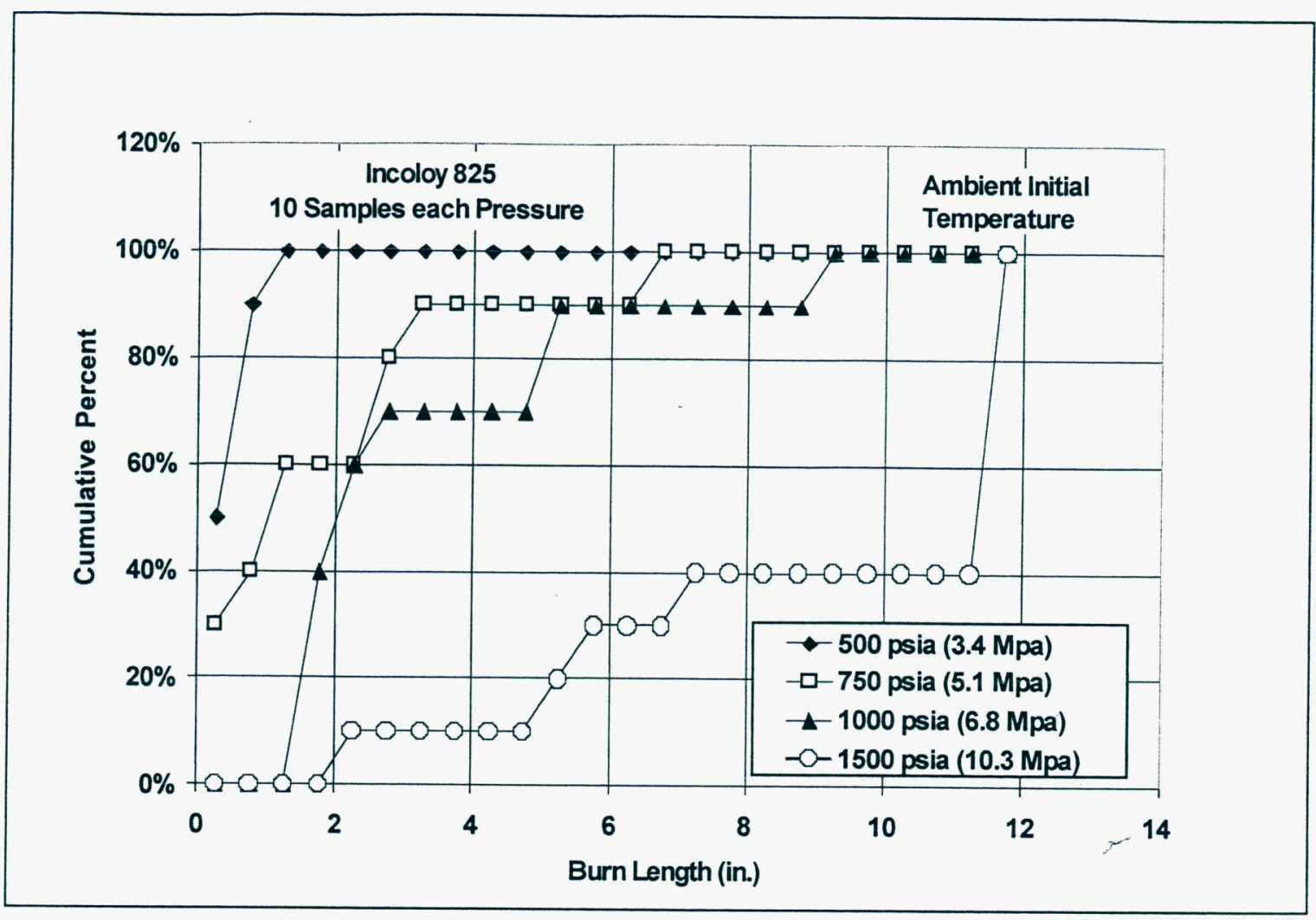

Figure 5. Inconel 825 Cumulative Burn Length Distributions

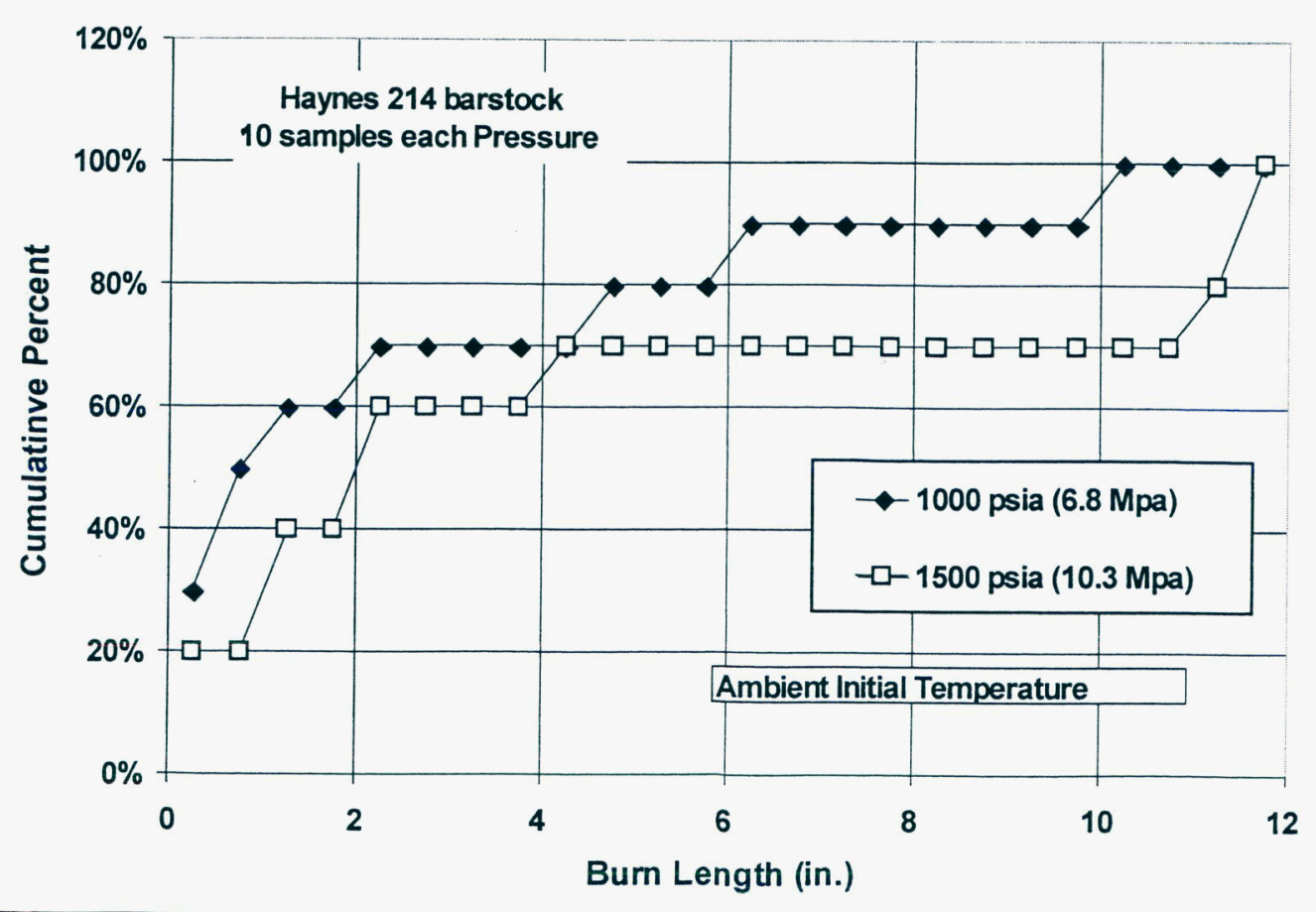

Figure 6. Haynes ${ }^{\circledR} 214^{\mathrm{TM}}$ Cumulative Burn Length Distributions 


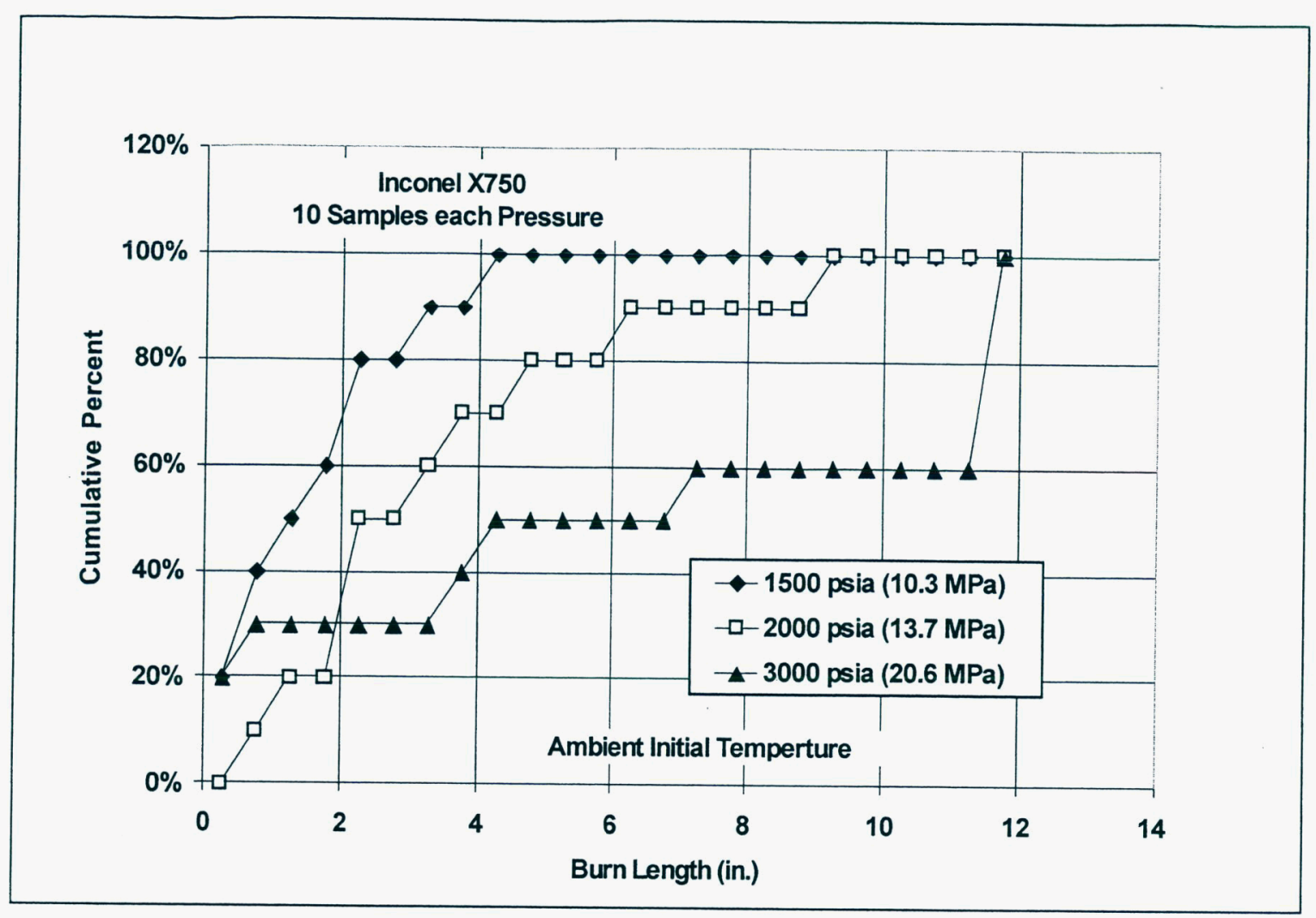

Figure 7. Inconel ${ }^{\circledR}$ X750 Cumulative Burn Length Distributions

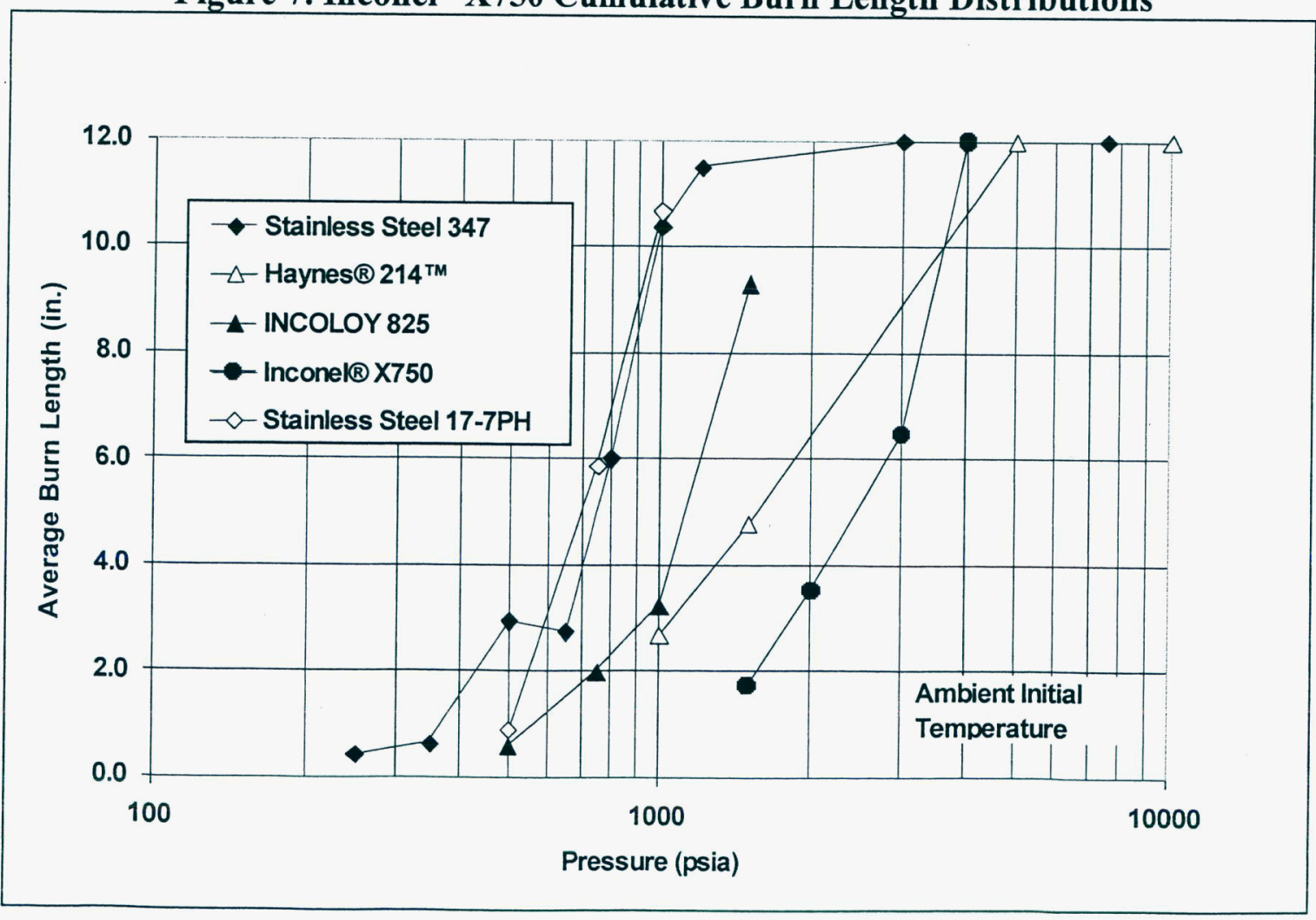

Figure 8. Comparative Average Burn Lengths for Five Metals 


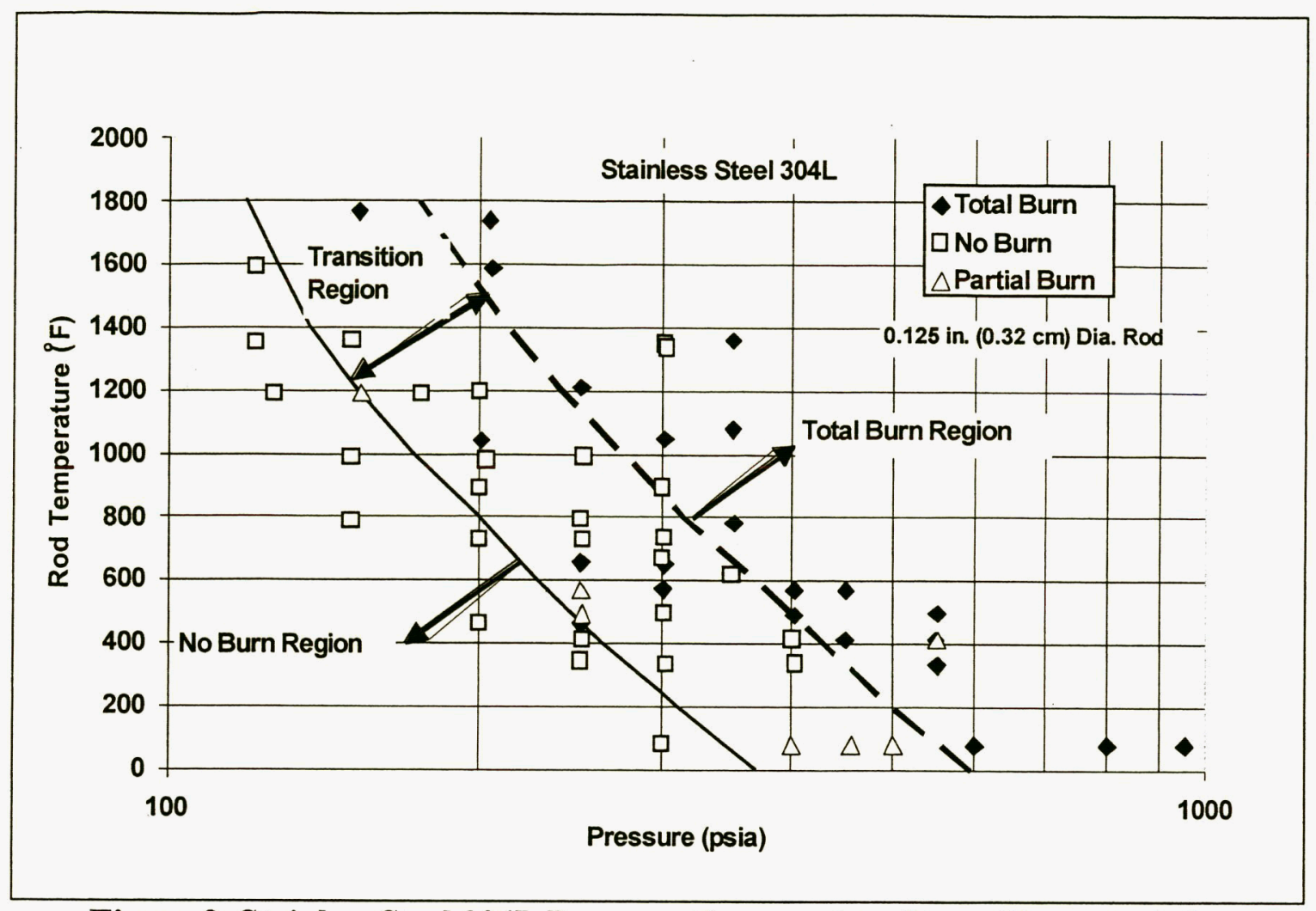

Figure 9. Stainless Steel 304L Pressure-Temperature Burn Characteristics

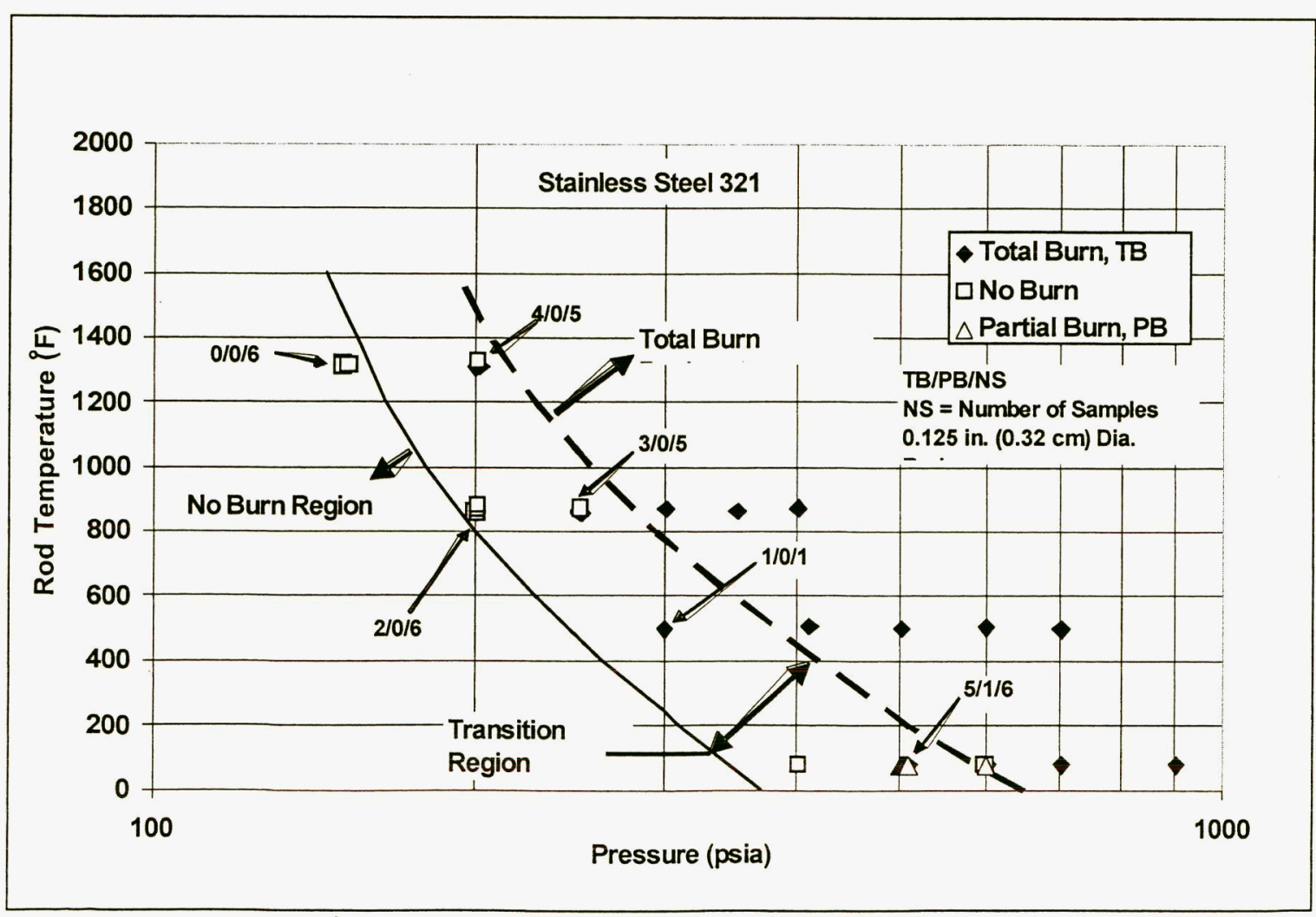

Figure 10. Stainless Steel 321 Pressure-Temperature Burn Characteristics 


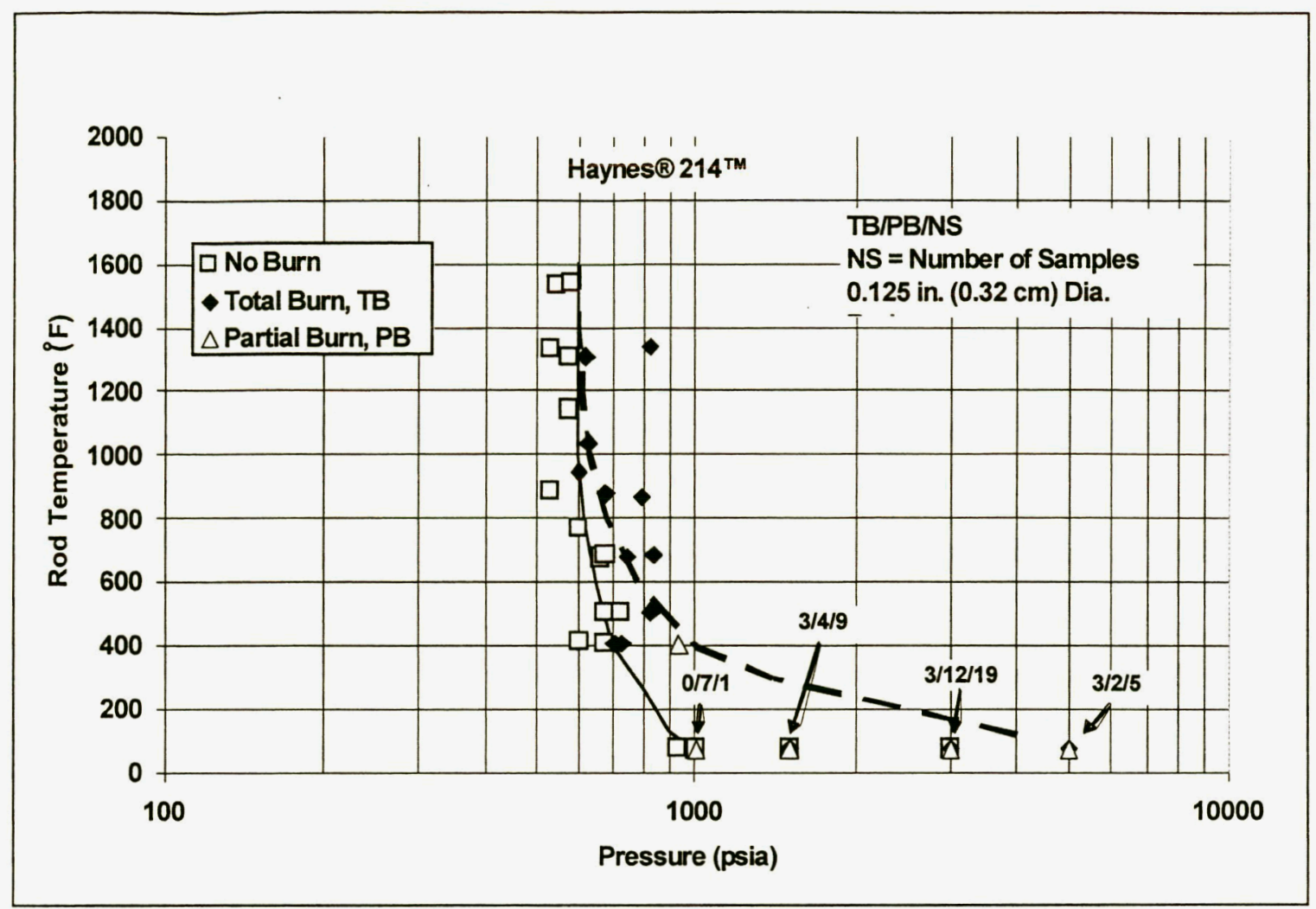

Figure 11. Haynes ${ }^{\circledR} 214^{\mathrm{TM}}$ Pressure-Temperature Burn Characteristics

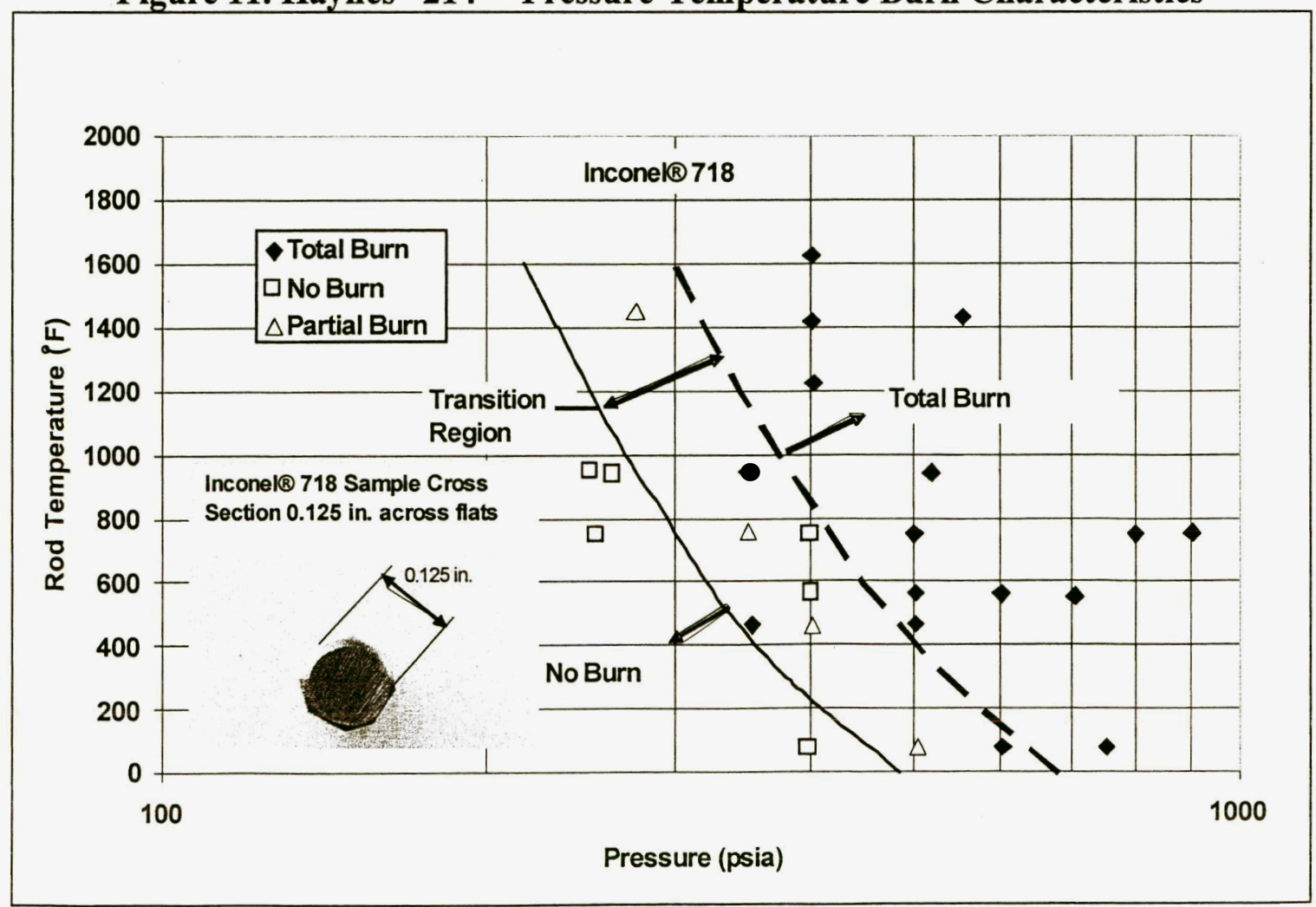

Figure 12. Inconel ${ }^{\circledR} 718$ Pressure-Temperature Burn Characteristics 


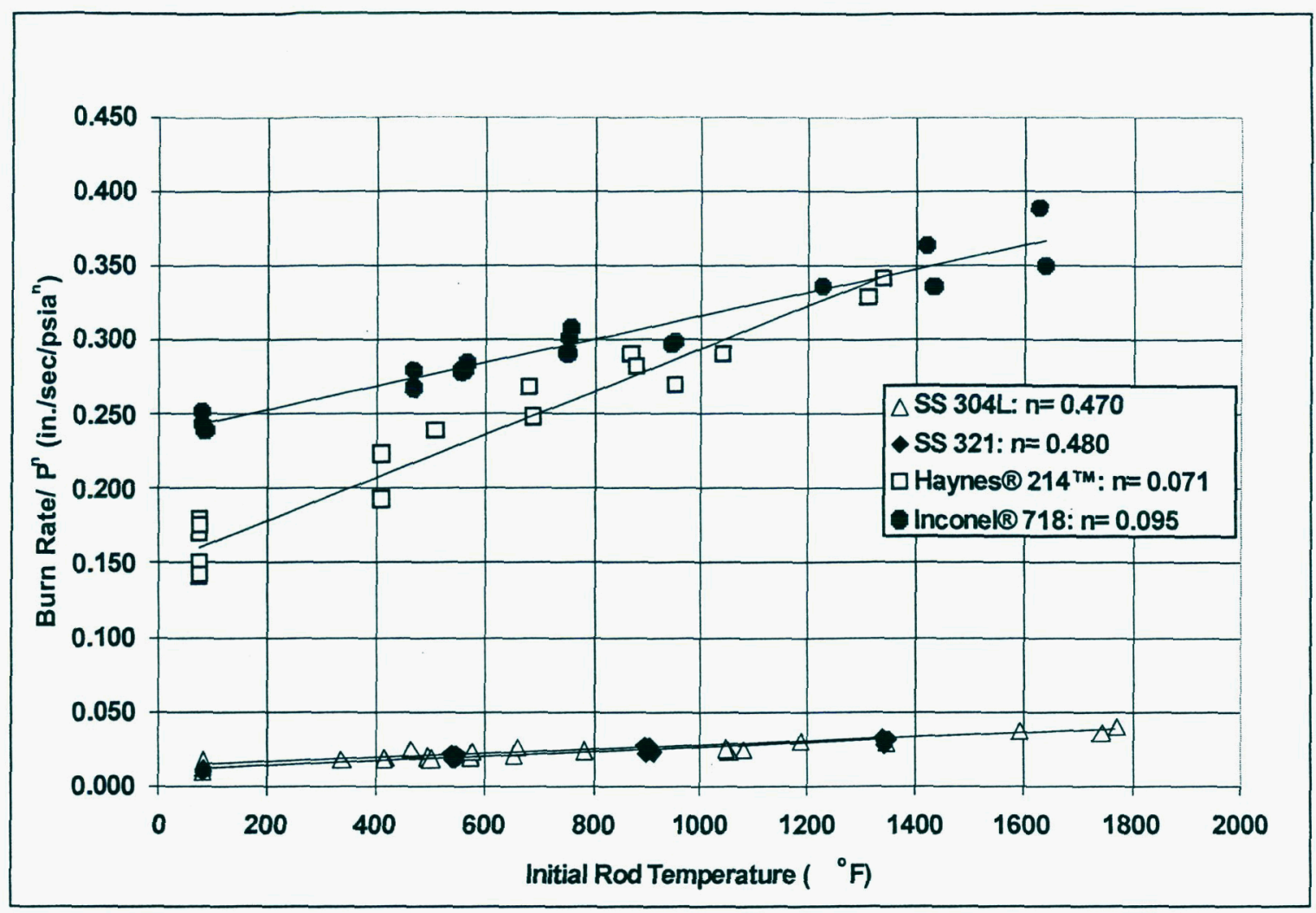

Figure 13. Pressure-Temperature Burn Rates for Quasi-Steady Conditions 